\title{
O024. Transcutaneous supraorbital nerve stimulation enhances somatosensory thalamic activity in migraine between attacks: a central mechanism of clinical efficacy?
}

\author{
Davide Di Lenola ${ }^{1 *}$, Gianluca Coppola ${ }^{2}$, Mariano Serrao ${ }^{1}$, Cherubino Di Lorenzo ${ }^{3}$, Francesco Pierelli ${ }^{1}$ \\ From Abstracts from the 1st Joint ANIRCEF-SISC Congress \\ Rome, Italy. 29-31 October 2015
}

\section{Background}

In a recent randomized double-blind sham-controlled study the Cefaly ${ }^{\circledR}$, a novel transcutaneous supraorbital electrostimulation device, has been successfully used as a prophylactic treatment for episodic migraine. The possible mechanisms of action through which the device is able to induce clinical improvement in migraine are not known. In the present study, we investigated whether Cefaly ${ }^{\circledR}$ may act centrally at the thalamocortical/cortical level.

\section{Methods}

To explore the central mechanisms of action of Cefaly ${ }^{\circledR}$, we recorded the somatosensory evoked potentials (SSEPs) before, and in the subsequent two times after one session of supraorbital stimulation lasting $20 \mathrm{~min}$ in 10 migraine without aura patients between attacks. We measured the N20-P25 amplitudes on the low-frequency-SSEP, and, after applying a band-pass filter $(450-750 \mathrm{~Hz})$, maximal peak-to-peak amplitudes of the pre-synaptic, reflecting thalamocortical activity, and post-synaptic, reflecting primary cortical activation, high-frequency oscillations (HFOs).

\section{Results}

Pre-synaptic HFO amplitudes, reflecting somatosensory thalamocortical activity, significantly increased after the stimulation (from $0.035 \mathrm{~V}$ to $0.058 \mathrm{~V}, \mathrm{p}<0.01$ ), whereas both the low-frequency N20 SSEP component and postsynaptic HFOs were unaffected.

\section{Conclusions}

Present data might support the hypothesis that Cefaly ${ }^{\mathbb{R}}$ acts centrally through increased thalamocortical activity induced by the neurostimulation. It is of obvious interest to verify whether these device-induced changes might persist in the long-term after 3-month daily preventive stimulation, and if they follow clinical improvement.

Written informed consent to publish was obtained from the patient(s).

\section{Authors' details}

"Sapienza" University of Rome Polo Pontino, Department of Medico-Surgical Sciences and Biotechnologies, Latina, Italy. ${ }^{2}$ G.B. Bietti Foundation IRCCS, Department of Neurophysiology of Vision and Neuro-ophthalmology, Rome, Italy. ${ }^{3}$ Don Carlo Gnocchi Onlus Foundation, Milan, Italy.

Published: 28 September 2015

\section{doi:10.1186/1129-2377-16-S1-A160}

Cite this article as: Di Lenola et al:: 0024. Transcutaneous supraorbital nerve stimulation enhances somatosensory thalamic activity in migraine between attacks: a central mechanism of clinical efficacy? The Journal of Headache and Pain 2015 16(Suppl 1):A160

\footnotetext{
* Correspondence: davidedilenola88@libero.it

" "Sapienza" University of Rome Polo Pontino, Department of Medico-Surgical

Sciences and Biotechnologies, Latina, Italy

Full list of author information is available at the end of the article
} creativecommons.org/licenses/by/4.0), which permits unrestricted use, distribution, and reproduction in any medium, provided the original work is properly cited. The Creative Commons Public Domain Dedication waiver (http://creativecommons.org/publicdomain/ zero/1.0/) applies to the data made available in this article, unless otherwise stated. 